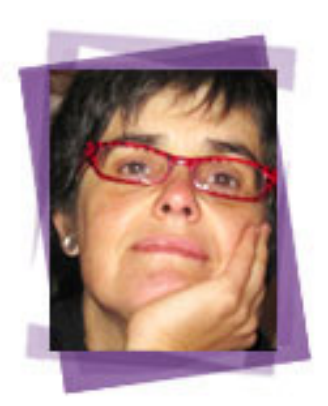

\title{
La traducció xarxa: utopies i distopies
}

Marta Estella Clota

Universitat Autònoma de Barcelona

\section{Resum}

Aquest article presenta una anàlisi dels canvis disruptius que experimenta actualment la traducció, conseqüència de l'emergència del web $2.0 \mathrm{com}$ a nou paradigma social i tecnològic, i de la globalització del treball i dels mercats. Conclou amb un apunt sobre les oportunitats que l'economia del coneixement obre al treball lingüístic.

\section{Paraules clau}

traducció col·laborativa, traducció social, traducció oberta, traducció generada per l'usuari, xarxa, web 2.0

\section{Introducció}

Els sistemes de treball de molts sectors professionals han experimentat canvis disruptius els darrers anys, com a resultat de l'extensió d'eines i serveis de web 2.0, o del paradigma 2.0, per emprar una fórmula no tecnocèntrica que permet emfasitzar la doble dimensió d'un fenomen que és tecnològic, però també, i sobretot, social (Estella, 2009).

En la dimensió tecnològica, el paradigma 2.0 se sosté en l'abundància d'ample de banda i de capacitat de processament, en una economia dels bits deflacionista en què els costos marginals tendeixen a zero, una tendència que va en paral-lel amb el creixement de la informàtica en núvol, és a dir, de sistemes basats en «ordinadors en xarxa que distribueixen capacitat de processament, aplicacions i grans sistemes a moltes màquines» (Johnson, Levine i Smith, 2009: 12). La informàtica en núvol permet oferir el software com a servei: la usuària utilitza el navegador web de l'ordinador o d'altres dispositius connectats a la xarxa per entrar en una aplicació, treballar-hi i desar-hi les dades que hi genera, en comptes de tenir les aplicacions i les dades allotjades al seu ordinador. El gestor de correu Gmail i l'aplicació d'ofimàtica Google Docs són dos exemples coneguts de software com a servei.

El caràcter deflacionista de l'economia dels bits ha portat al desenvolupament de diferents models de negoci que sostenen les empreses de serveis 2.0, entre els quals hi ha el model basat en la publicitat, el model basat en l'oferta de dades a tercers, o el model freemium, és a dir, l'oferta d'un servei gratuït, en una versió bàsica, a una gran massa d'usuàries, que el popularitzen, i en una oferta professional, de pagament, amb més prestacions i més capacitat d'emmagatzematge, adreçada a una minoria que està disposada a pagar per utilitzar-la (Anderson, 2009).

En la dimensió social, el web és cada cop més una plataforma que les persones s'apropien per a crear i difondre continguts, per descobrir-se i relacionar-se; una plataforma que permet col-laborar en projectes en temps real, que ajuda a establir connexions, que facilita el seguiment de múltiples canals d'informació, que serveix d'aparador professional i personal, i d'altaveu del treball amateur, i que fa possible la conversa amb expertes i referents de qualsevol àmbit acadèmic o professional, altrament 
inaccessibles fora de cercles reduïts. En el paradigma 2.0, les persones esdevenen, cada cop més, prosumidores, és a dir, productores i consumidores alhora de continguts, una tendència que s'accelera pel fet que es redueix notablement la corba d'aprenentatge respecte de les aplicacions d'escriptori més tradicionals, i també pel caràcter gratuït de molts dels serveis 2.0.

Democratització, amateurisme i gratuïtat són tres trets constitutius del paradigma 2.0 que s'estenen rizomàticament $i$ arriben a desafiar molts perfils professionals tal com els hem entès fins ara. Potser l'exemple més conegut de desafiament és la Viquipèdia, un projecte en què una gernació de persones voluntàries esdevenen autores o editores d'una enciclopèdia en línia, sense que se'ls demani cap acreditació acadèmica ni professional. El seu sistema de control es basa en el requisit que la informació ha de poder ser contrastada en altres fonts i el fet que tothom pot editar i, per tant, esmenar errors, juntament amb una política editorial i unes directrius per a la publicació. També n'és un bon exemple el periodisme ciutadà, és a dir, el periodisme fet per persones que, sense tenir necessàriament una formació com a professionals d'aquest sector, contribueixen a crear mitjans de comunicació i a fornir els mitjans de continguts, gràcies a eines gratuïtes i fàcils d'utilitzar: blogs, fòrums, serveis per a la publicació de fotografies, etc. En tenim altres exemples en la realització i la publicació de vídeos, fins fa poc reservades a les professionals, i que actualment serveis com YouTube o Vimeo han posat a l'abast de moltes persones que editen i publiquen com a amateurs; o, en un altre àmbit, la publicació de ressenyes de llibres en plataformes com Amazon i Google Llibres per part de qualsevol lectora. La traducció, com també els altres sectors professionals vinculats a les llengües, no escapa a aquest desafiament.

\section{La traducció xarxa}

Els serveis i eines de web 2.0 orientats a la col-laboració i la realització de projectes han facilitat la creació i difusió d'entorns per a la traducció, per part de professionals, però també d'amateurs. En un contínuum que va dels entorns preferentment professionals als entorns preferentment amateurs, hi trobem xarxes professionals de traducció, wikis adreçats a la traducció, diccionaris creats per les usuàries, pràctiques de subtitulació en línia i localització voluntària de webs. Es tracta d'un conjunt de fenòmens que Perrino (2009, p. 62) aplega sota el concepte de 'traducció generada per la usuària', User-generated Translation (UGT) en l'original. A la mateixa Viquipèdia, una bona part dels continguts són traduccions, sobretot de l'anglès, fetes per persones a les quals no es pressuposa cap expertesa com a traductores professionals. Com tampoc no es pressuposa cap expertesa professional a les persones que fan subtitulacions de vídeo en línia, una pràctica que s'estén a l'empara de serveis com DotSub o YouTube, que hi posen els mitjans, i de l'increment de la diversitat lingüística a internet, com a resultat, en part, de l'eclosió dels continguts audiovisuals a la xarxa dels darrers anys i, per tant, de la llengua oral, la llengua real dels parlants (Moreno Cabrera, 2008).

'Traducció generada per la usuària' té el valor de recollir el conjunt de fenòmens que en el paradigma 2.0 es produeixen al voltant de la traducció i destacar el paper actiu de les usuàries, que sovint actuen com a prosumidores de traducció. No obstant això, m'estimo més d'emprar el terme 'traducció xarxa', per destacar, tant el fet que aquest nou escenari per a la traducció es produeix cada cop més en l'entorn web, com els trets propis de la societat xarxa que hi són inherents: la fragmentació i la individualització dels processos de treball, l'organització del treball basada en les capacitats de cadascú més que no en l'organització mateixa de les tasques, l'anihilació del temps i la superació de l'espai, l'estructura oberta, el dinamisme, la flexibilitat, l'adaptabilitat, etc. (Castells, 2000: 501-506).

\section{Utopies de la traducció xarxa: una nova Arcàdia}

La visió més idíl.lica i utòpica de la traducció xarxa porta a transitar pel costat amable d'aquest nou escenari, una nova Arcàdia constituïda per les diverses manifestacions de la traducció social, entesa com a traducció realitzada per una comunitat d'usuàries. Dins la traducció social, podem situar-hi la 
traducció de codi obert, és a dir, els projectes de localització social de molt software de codi obert i software lliure, com els que desenvolupa Softcatalà per a la llengua catalana. El fet que es tracti de codi obert facilita les localitzacions per part de la comunitat, i, de fet, hi ha projectes que es posicionen clarament a favor de la diversitat lingüística en el seu ideari, com Ubuntu: «la gent ha de poder utilitzar les eines de programari en el seu propi idioma» (Ubuntu, v. 10.04 LTS, «Quant a»).

També en l'àmbit de la traducció social, hi ha iniciatives que tenen com a finalitat facilitar l'accessibilitat lingüística dels continguts en línia distribuïts en una plataforma o mitjà. És el cas del TED Open Translation Project i del projecte Lingua de Global Voices que ofereixen la traducció dels continguts originals, en anglès, a d'altres llengües, gràcies a les contribucions de voluntàries, professionals o no, que se senten compromeses amb els valors que difonen aquests continguts. Com a compensació, veuen reconeguda públicament la seva tasca de traducció en les mateixes plataformes que difonen els continguts traduïts. En paraules d'Ethan Zuckerman, president de Global Voices: «But maybe translation doesn't need to be so difficult and expensive. Maybe it's something that interested, talented people will do for free, if given the right opportunities and incentives.» (Zuckerman, 2009)

Podem situar, així mateix ,en el marc de la traducció social la traducció activista, com la del projecte Babels, una xarxa internacional de traductores voluntàries que té per finalitat cobrir les necessitats d'interpretació en els fòrums socials mundials i regionals, i que es val d'entorns col-laboratius per realitzar la seva tasca.

Un altre vessant de la traducció social és el fenomen de la traducció de les fans; n'és un exemple el projecte Lost-Perduts, que ha aplegat seguidors de la sèrie per traduir, subtitular i publicar-ne els capítols en català, i també les traduccions no oficials de Harry Potter realitzades per lectores de la saga.

Hi ha altres manifestacions de la traducció social, com les plataformes en línia per a comunitats de traductores i per a la prestació de serveis de traducció. N'hi ha que s'orienten més a un espai per a l'intercanvi de serveis entre prosumidores de traducció, persones que no necessàriament són traductores professionals: Cucumis, Conyac o WikiTranslate d'altres que presenten un perfil més professional, com ProZ o Translators Café, que té com a actiu important els fòrums i els glossaris generats per la comunitat. Un cas a part són els diccionaris socials, entre els quals trobem projectes amb una orientació més oberta i comunitària, com el Vicicionari, i d'altres, com en el cas de Logos amb un enfocament més professional.

A diferència d'aquestes plataformes, que tenen en comú la focalització en la dimensió social i relacional, hi ha també projectes en què destaca la dimensió tecnològica, com Tradubi, una aplicació web per a la traducció social, de codi obert i software lliure, basada en el motor de traducció d'Apertium, que es proposa «construir una plataforma per a la personalització i la millora de sistemes de traducció automàtica, i oferir un entorn per a posteditar traduccions màquina i compartir-les» (SánchezCartagena; Pérez-Ortiz, 2010: 47).

La traducció social, però, té un abast limitat, en comparació amb altres sectors que s'han expandit extraordinàriament a l'empara del paradigma 2.0. Com afirma Perrino:

\footnotetext{
I assume that UGT tools do not tend to catch the interest and participation of the Internet masses, for translation is hardly perceived by the general public as a rewarding activity - both in terms of money and glory. While the Web is overcrowded with would-be musicians, filmmakers, photographers and journalists who pursue their dream and gladly accept no compensation to promote the results of their hobbies, the same cannot be said in the field of translation. The very nature of the activity, which is somehow performed in the shadow of the source text writer and rarely leads to fame and prestige, is not compatible with the Web 2.0 amateur, who ultimately seeks recognition. (Perrino, 2009: 72-73)
}

Ara bé, si atenem l'impacte pel que fa al nombre d'usuàries i de funcionalitats associades a la traducció, és Google qui ha revolucionat la traducció a la xarxa, en la doble dimensió, social i tecnològica, mitjançant aplicacions i serveis com els següents: Google Translate i el giny per incorporar Google 
Translate als webs, Cerques traduïdes, Google Translator Toolkit, i més recentment Google Goggles Translation, un servei que combina realitat augmentada i traducció, és a dir, la possibilitat de reconèixer el text d'una imatge capturada per la càmera d'un dispositiu mòbil i oferir-ne la traducció. A aquestes aplicacions i serveis, cal afegir-hi els de subtitulació de vídeo i de traducció de veu incorporats a Youtube, que Google va adquirir el 2006, i el programa Google in Your Language, que permet a les usuàries traduir la interfície i les pàgines d'ajuda a qualsevol llengua. La revolució de Google afecta també l'entorn més professional: el volum d'informació indexat pel cercador possibilita la utilització del web com a corpus lingüístic, i de fet, d'acord amb el projecte MeLLANGE, citat per Ferraresi (2009: 1), prop del $95 \%$ de les traductores i estudiants de traducció utilitzen el web per a tasques relacionades amb la traducció, mentre que menys de la meitat compilen corpus.

\section{Distopies de la traducció xarxa: la maquiladora virtual}

En contrast amb la visió utòpica que acabem de descriure, la traducció xarxa també es constitueix sobre distopies: és l'estadi actual d'un procés de pèrdua de control de les traductores sobre la tecnologia que utilitzen i sobre la seva pròpia feina, un procés que comença quan les agències de traducció integren els gestors de memòries de traducció en els projectes de traducció tècnica. A partir d'aleshores, la traductora es veu desposseïda dels beneficis que havia aconseguit amb l'ús de memòries de traducció sobre les quals tenia plens poders, i la seva feina se centra a treballar sobre els segments que rep, els quals tradueix amb el gestor que l'agència ha establert com a eina de treball (Garcia 2009: 201-202).

Els processos de traducció evolucionen cap a la traducció realitzada en un entorn web, a qualsevol hora, per part de professionals que estiguin disponibles, independentment de la seva ubicació i de les eines d'escriptori que tinguin (Beninatto i DePalma, 2008: 51), fins al punt que comença a emergir l'ideal de la traducció com a subministrament, és a dir, la disponibilitat permanent de l'accés a serveis de traducció, tal com tenim accés a l'aigua o la llum (Garcia i Stevenson, 2009: 29). Aquesta evolució accentua la pèrdua de control i la despossessió de la traductora, en la mesura que aquesta realitza la seva tasca en un servidor aliè sobre el qual té uns drets d'accés mínims i limitats al temps que dura la seva vinculació a un projecte de traducció, i, en conseqüència, ja no disposa del producte resultant de la seva feina. D'altra banda, la facilitat que presenta el treball en aquests entorns web fa que l'expertesa tècnica adquirida per moltes traductores pioneres en l'ús de gestors de memòries de traducció hagi deixat de ser un valor afegit.

Hi ha també dos factors importants en aquest nou escenari. En primer lloc, el fet que el mercat es globalitza i s'obre el negoci de la intermediació entre empreses clientes, d'una banda, i traductores o agències de traducció, de l'altra, per a la subcontractació a escala planetària de projectes de traducció i, especialment, de localització. Empreses com Aquarius, http://twitter.com/translationjobs i, en menor mesura, One Hour Translation , funcionen d'acord amb aquest model de negoci. El segon factor té a veure amb les expectatives d'immediatesa i gratuïtat que el paradigma 2.0 ha universalitzat entre les usuàries de la xarxa, i la prevalença de la satisfacció per damunt de la qualitat: «[...] with the speed we now desire, assessment is tempered by fitness for use: if users are satisfied with results, anything more is a waste of resources» (Garcia, 2009: 206).

La culminació del procés que hem descrit es produeix, però, amb la introducció de la subcontractació de massa (crowdsourcing) en projectes relacionats amb la traducció i la localització. Els darrers anys, diverses empreses que ofereixen serveis a internet han recorregut a la comunitat d'usuàries per ampliar el nombre de versions lingüístiques de la seva interfície; és el cas de Twitter, Facebook, o Google, amb el programa Google in Your Language ja esmentat. Es tracta d'una derivació de la traducció de codi obert, amb la diferència, substancial, que aquí no hi ha projectes de codi obert, sinó empreses que amplien la segmentació del mercat en termes lingüístics gràcies al treball voluntari de la comunitat 
d'usuàries, en un context en què es dilueixen els límits entre l'altruisme idealista i la contribució voluntària a empreses comercials.

Però la veritable subcontractació de massa arriba quan plataformes com Mechanical Turk ofereixen col-laborar en projectes relacionats amb la traducció i la llengua en general. Mechanical Turk és una plataforma d'Amazon en la qual una empresa, una organització o un particular pot oferir la realització d'una «tasca d'intel.ligència humana» per a la qual fixa els requisits i les condicions econòmiques. Qualsevol persona que es registri a la plataforma pot aspirar a realitzar una de les tasques ofertes i rebre una retribució si qui ha fet l'oferta n'aprova el resultat. D'acord amb Iperoitis (2010), entre les persones que treballen a Mechanical Turk predominen les dones i la gent jove, un $34 \%$ viuen a l'Índia i només un $46,80 \%$ als EUA, i un nombre creixent de treballadores utilitzen la plataforma per obtenir ingressos per a primeres necessitats o per a extres, davant de les que hi participen com a passatemps recompensat. Aquesta situació ha fet que sovint Mechanical Turk sigui considerada una gran maquiladora virtual. Mentre escrivim aquest article, trobem en l'oferta de Mechanical Turk projectes com els següents: traduir un text de l'anglès al basc, transcriure un vídeo de YouTube, instal-lar una aplicació per a l'iPad i escriure'n una ressenya favorable, transcriure missatges de veu ficticis en espanyol, escriure un apunt en un blog per promocionar un producte, i escriure una història sobre els motius que han portat algú a triar el nom del seu fill, entre molts d'altres.

En aquest nou context, la traducció s'amateuritza, com s'amateuritzen altres feines relacionades amb la llengua. Les traductores esdevenen «disembodied entities in the internet ether, their supply constantly replenished from the world's pool of bilingual talent» (Garcia, 2007: 56); la professionalització de la traducció, en definitiva, esdevé una anomalia.

\section{Cloenda}

La traducció, tal com l'hem entès fins ara, està sotmesa a un fort desafiament, a causa de les grans transformacions socials i econòmiques que comporten l'expansió dels serveis de web 2.0 i la globalització dels mercats i del treball. Però alhora aquestes mateixes transformacions obren camins per a les professionals de la llengua. D'una banda, hi ha un creixement important del mercat de serveis lingüístics — del 13,15\% anual (Kelly i Stuart, 2010: 3)—, com a resultat de les necessitats de traducció que genera la globalització. D'altra banda, en l'economia del coneixement el treball es caracteritza pel treball en equip i la cooperació; llengua i cultura hi són, doncs, trets essencials (Williams, 2010: 20) i ofereixen un espai per a nous perfils laborals. Les professionals de la traducció tenen l'oportunitat, i la necessitat, d'apropiar-se dels serveis de web 2.0 per projectar el valor específic que poden aportar en aquesta nova situació.

\section{Referències}

Anderson, Chris (2009) Free: the future of a radical price. New York: Hyperion Books.

Beninatto, Renato S.; DePalma, Donald A. (2008) "Collaborative translation", Multilingual, Resource Directory \& Index 2007: 49-51. 
Castells, Manuel (2000) The Information Age. Economy, Society and Culture. Vol. I: The Rise of the Network Society. Oxford; Malden, MA: Blackwell. 1a edició: 1996.

Estella, Marta (2009) "Els serveis lingüístics en el paradigma 2.0", Llengua i Ús, 46 (tercer quadrimestre).

Ferraresi, Adriano (2009) "Google and beyond: web-as-corpus methodologies for translators". Tradumàtica, 7.

Garcia, Ignacio (2007) "Power shifts in web-based translation". Machine Translation, 21 (1):55-68.

Garcia, Ignacio (2009) "Beyond translation memory: Computers and the Professional". The Journal of Specialised Translation, 12: 199-214.

Garcia, Ignacio.; Stevenson, Vivian (2009). "Translation trends and the social web". Multilingual, 103, 20 (3): 28-31.

Iperoitis, Panagiotis G. (2010) "Demographics of Mechanical Turk". CeDER Working Papers. Faculty Digital Archive. New York University. http://archive.nyu.edu/handle/2451/29585. Data de consulta: 29.06.10.

Johnson, L.; Levine, A.; Smith, R. (2009). Informe Horizon. Austin, Texas: The New Media Consortium. Traducció al català de The 2009 Horizon Report. www.nmc.org/pdf/2009-Horizon-Report-ca.pdf. Data de consulta: 29.05.10.

Kelly, Nataly; Stewart, Robert G. (2010) "The Top 35 Language Service Providers". Extracte de "Language Services Market: 2010". Common Sense Advisory www.commonsenseadvisory.com Data de consulta: 30.06.10.

Moreno Cabrera, Juan Carlos (2008) "El multilingüismo y la globalización cultural del siglo XXI", conferència impartida a la UAB el 26 setembre. La citació és de Marta Estella (2008) "L'eclosió del multilingüisme a la xarxa", Marta Estella [apunt a blog] http://blogs.uab.cat/martaestellaclota/2008/10/13/laudiovisual-i-lexplosio-del-multilinguisme-a-la-xarxa/ Data de consulta: 07.06.10.

Perrino, Severio (2009) "User-generated Translation: The future of translation in a Web 2.0 environment". The Journal of Specialised Translation, 12: 55-78.

Sánchez-Cartagena, Víctor M.; Pérez-Ortiz, Juan Antonio (2010) "Tradubi: Open-Source Social Translation for the Apertium Machine Translation Platform", The Prague Bulletin of Mathematical Linguistics, 93: 47-56.

Williams, Glyn (2010) “Inside knowledge”, The Linguist, 49 (2): 20-21.

Zuckerman, Ethan (2009, 13 maig) «TED embraces social translation», My Heart's in Accra [apunt a blog], http://www.ethanzuckerman.com/blog/2009/05/13/ted-embraces-social-translation/ Data de consulta: 07.06.10. 